\title{
Ameloblastic Fibro-Odontoma in the Mandibular Incisor of a Cow
}

Toshiaki MASEGI, Tadaaki KUDO ${ }^{1)}$, Masashi KAWADA ${ }^{2)}$, Tokuma YANAI, and Katsumoto UEDA

Departments of Veterinary Pathology, ${ }^{1)}$ Veterinary Surgery, Faculty of Agriculture, Gifu University, 1-1 Yanagido, Gifu 501-11 and

${ }^{2)}$ Meat Inspection Office of Gifu Prefecture, 3-167-1 Hayashimachi Ogaki-shi, Gifu 503, Japan

(Received 27 January 1993/Accepted 27 July 1993)

ABSTRACT. Odontogenic neoplasm was found in the mandibular incisor area of a 3-year-old Japanese black ox. Macroscopically, the cut surface was white and firm with streaks of hard tissue. Histologically, the tumor was composed of enamel organ structures with odontogenic hard tissue in fibromatous areas. It was diagnosed as ameloblastic fibro-odontoma. The absence of the 4th permanent incisor confirmed by radiography and microscopic examination strongly suggests that this tumor has been originated from the tooth germ tissues of the permanent left 4th incisor.-KEY wORDs: ameloblastic fibro-odontoma, bovine, odontogenic tumor.

J. Vet. Med. Sci. 56(1): 157-159, 1994

Odontogenic tumors arising from dental formative tissues are rarely reported in domestic animals such as the ox $[4-6,14,18,24]$. Epithelial odontogenic tumors accounted for less than $0.7 \%$ of all oral neoplasms diagnosed in domestic animals by the pathology service of New York State College of Veterinary Medicine [24]. Veterinary literature showed only 25 bovine cases [1-15, $17,19-21,23,24]$, including our previously reported case of ameloblastic odontoma [12]. This paper describes the pathological characteristics and certain radiographic features of another odontogenic tumor in a 3-year-old Japanese black ox. The ox with a mass $(7 \times 10 \times 14 \mathrm{~cm})$ extending from the mandibular incisor region to rostral was sent to the meat processing plant. Pertinent clinical history was not available. The tumor was gray in color and the cut surface was white and firm with scattered irregular white foci $(2 \times 5 \mathrm{~mm}$ to $10 \times 20 \mathrm{~mm})$, and thin streaks of hard tissue at the peripheral region. Radiographic examination showed a uniform semi-opaque mass with

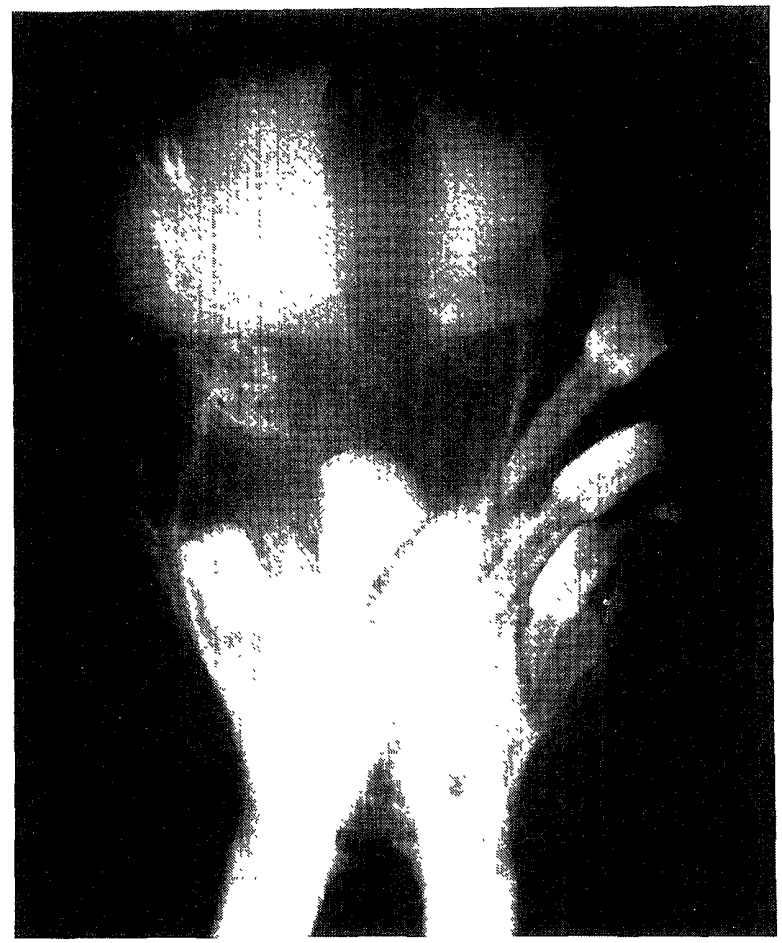

Fig. 1. Radiophotograph of the mandibular incisor region illustrating a few irregular radio-opaque masses. scatted linear and irregularly-shaped opaque shadows. The roots of the 1st and 2nd permanent incisors were already complete, while that of the $3 \mathrm{rd}$ permanent incisor was nearly complete on both sides. The crown of the 4 th permanent incisor on the right side was already completed, whereas only a shadow could be detected. The 1st to 3rd permanent incisors on the left side were impacted under the tumor mass (Fig. 1). The specimen was fixed in $10 \%$ formalin and decalcified electrically with $5 \% \mathrm{HCl}$ solution. A sagittal section of the whole neoplasm was divided into 5-10 blocks for a complete representation of the topography of various components of the mass. The blocks were routinely processed into paraffin blocks and sections stained with hematoxylin and eosin.

At microscopic examination, fibromatous areas occupied a major part of the tumor mass (Figs. 2 and 5). These fibromatous areas consisted of sheets of cells resembling fibroblasts or fibrocytes having spindle-shaped nuclei accompanied by variable amounts of collagenous fibers

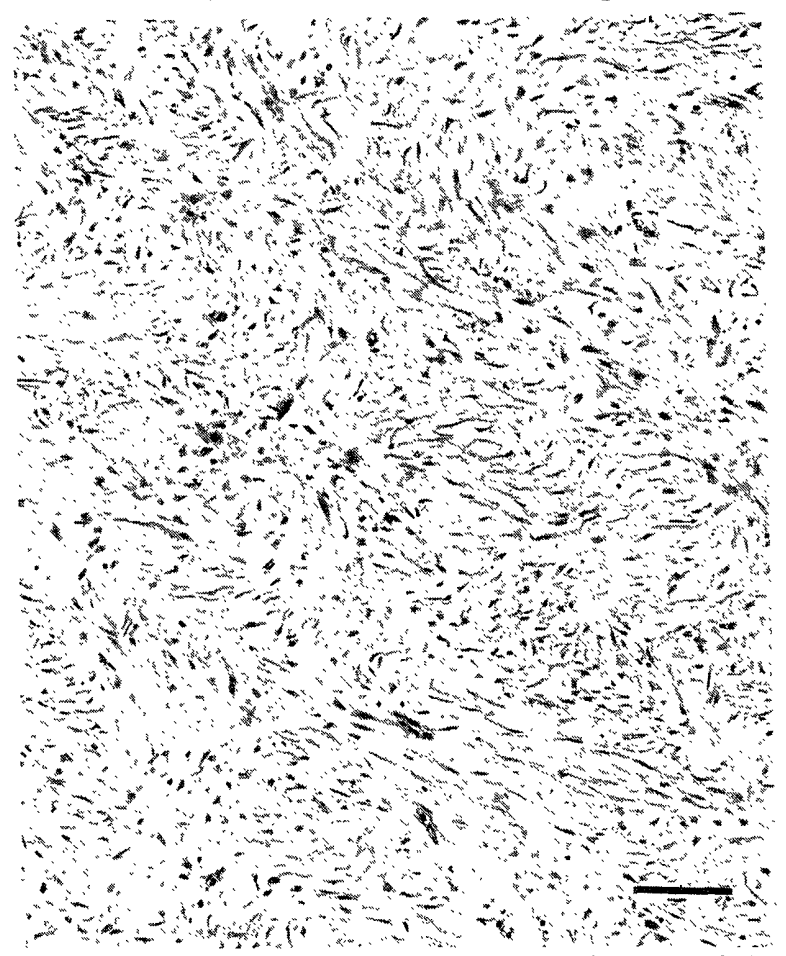

Fig. 2. Fibromatous area occupying the major part of the tumor mass. HE stain. Bar $=100 \mu \mathrm{m}$. 


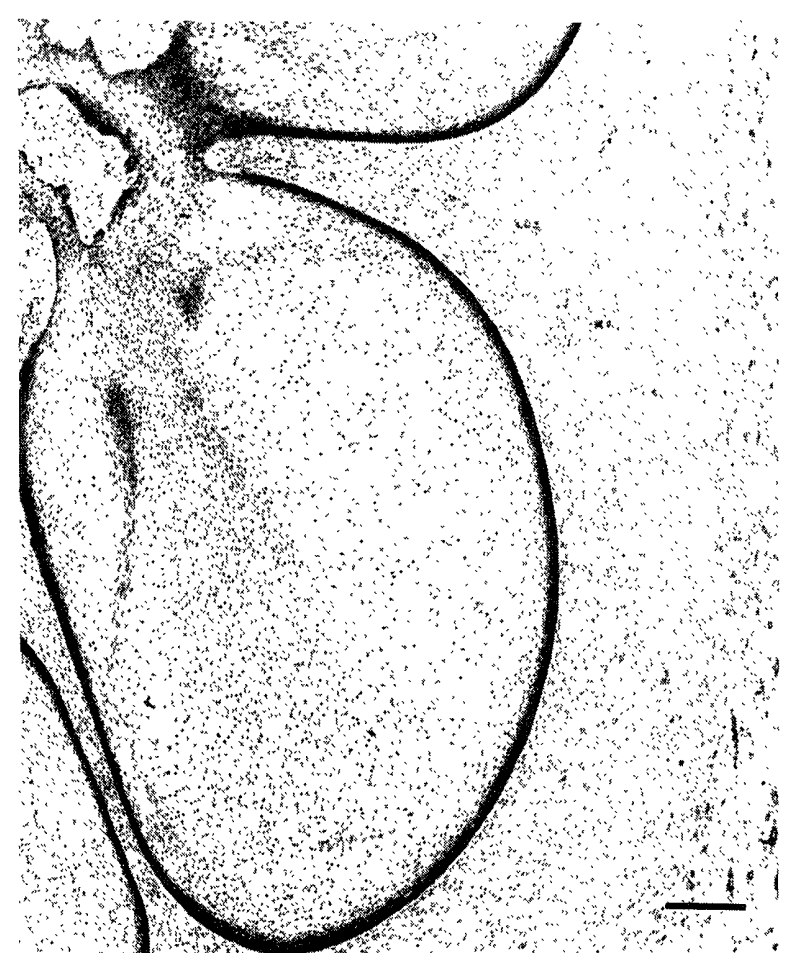

Fig. 3. Bell-stage enamel organ structure with formation of central stellate reticulum in the fibromatous area. HE stain. Bar $=200 \mu \mathrm{m}$.

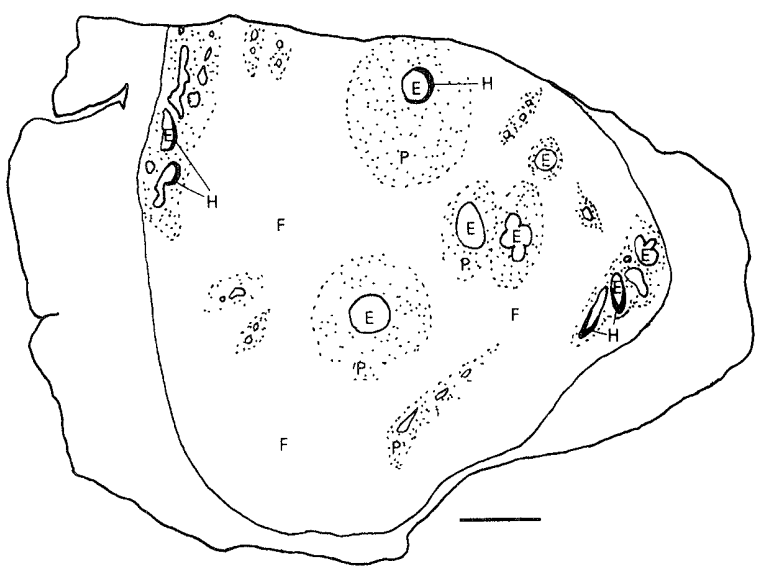

Fig. 5. Topographical mapping of sagittal section of the tumor. $\mathrm{E}$ : enamel organ, $\mathrm{P}$ : dental papilla, $\mathrm{H}$ : dental hard tissue, $\mathrm{F}$ : fibromatous area. $\mathrm{Bar}=1 \mathrm{~cm}$.

(Fig. 2). Organization into structures similar to that of ameloblastoma or ameloblastic odontoma was seen in some blocks (Figs. 3 and 4). No mitotic figure was observed in the fibromatous area. In the ameloblastomalike structure, epithelial components were thin restiform or physaliform cap-stage enamel organ structures. Surrounding the dentigerous epithelial layer was a framework of asteroid mesenchymal cells with numerous cytoplasmic processes giving an appearance quite similar to the dental papilla (Fig. 3). In the areas composed of epithelial and hard tissues with an ameloblastic odontomatous

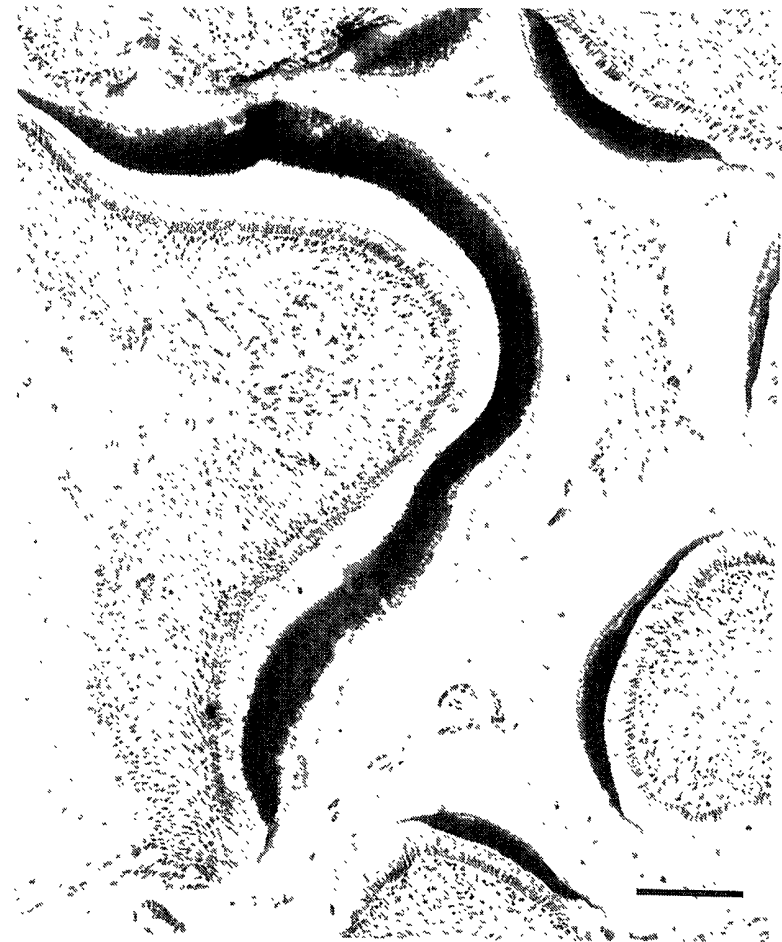

Fig. 4. Formation of irregular osteodentine and enamel between cylindrical ameloblasts and less differentiated odontoblasts. HE stain. Bar $=100 \mu \mathrm{m}$.

architecture, the epithelial components were well developed, having bell-stage enamel organ structures. Cells located at the basal area of the enamel cell layer were differentiated into cylindrical ameloblasts, while odontoblasts showed less differentiation. Small amounts of immature dentin and enamel were present between the ameloblastic and odontoblastic layers (Fig. 4). Calcification was rarely seen. The tumor grew intumescently and destroyed the front area of the mandible. The neoplastic tissue was not directly connected to tooth germ, impacted teeth, or the epithelium of the oral mucosa.

The classification of odontogenic tumors is arranged as a sequence following that of normal tooth development [14]. The tooth germ, which is supposedly the site of origin of odontogenic tumors, consists of ectodermal enamel organ and mesoblastic dental papilla. Thus tumors stemming from these dental germ tissue can have diverse histological patterns. These tumors may be roughly classified as epithelial, mesodermal or a mixture of the two $[12,22]$, although no consensus has been reached. Pindborg and Kramer [16] divided epithelial odontogenic tumors in humans into inductive and non-inductive types based on the inductive effect of one dental tissue on another. Gorlin's adaptation of Pindborg's scheme has been used to classify similar lesions in animals $[4-6,14,18$, 24]. In 25 cattle cases previously reported, ameloblastoma of the non-inductive type comprised 13 cases $[1,3,8-10$, $13,15,17,19-21,23]$. The other cases included 5 ameloblastic odontoma $[5,7,8,12,24], 4$ complex or compound odontomas $[20,23,24]$ and one each of 
ameloblastic fibroma [1], ameloblastic fibro-odontoma [11] and ameloblastic fibrosarcoma [2] belong to the inductive type of epithelial odontogenic tumors. There has been no report of a pure mesodermal type occurring in cattle [12]. Although the term "ameloblastic odontoma" is still used in veterinary pathology, in human oral pathology it encompasses two entities: ameloblastic fibro-odontoma (which has the general features of ameloblastic fibroma but also contains dentin and enamel) and odontoameloblastoma (which resemble an ameloblastoma but with the formation of dentin and enamel) [18]. The present case showed proliferation of both the epithelial and mesenchymal odontogenic elements with formation of dental hard tissues, and onontoblasts showed less differentiation. Therefore, it is unlikely that odontogenic hard tissue would occupy the major region of this neoplasm with passage of time to form complex odontoma.

The histological characteristics of this neoplasm were consistent with the diagnosis of ameloblastic fibroodontoma. All the cases of odontogenic tumors [1-15, 17, 19-21, 23, 24] have been found in cattle under 5 years of age. In $17(70 \%)$ of these cases, the tumor was located in the mandibular incisor region. In the present case, the absence of the 4th permanent incisor confirmed by radiography and microscopic examination strongly suggests that the origin of this neoplasm as the tooth germ tissues which were to be organized into the permanent left 4 th incisor. This case presents evidence of tooth germ origin of an odontogenic tumor in a bovine animal.

\section{REFERENCES}

1. Becker, M. 1974. Schewiz. Arch. Tierheilkd. 116: 189-192.

2. Binnington, J. A. and Adkins, K. F. 1972. J. Pathol. 108: 169-172.

3. Cheeme, A. H. and Shanin, H. 1974. Vet. Pathol. 11: 235-239.

4. Gorlin, R. J., Barron, C. N., Chaudhry, A. P., and Clark,
J. J. 1959. Am. J. Vet. Res. 20: 1032-1061.

5. Gorlin, R. J., Chaudhry, A. P., and Pindborg, J. J. 1961. Cancer 14: 73-101.

6. Gorlin, R. J., Meskin, L. H., and Brodey, R. 1963. Ann. New York Acad. Sci. 108: 722-771.

7. Gruys, E. 1975. Zentralbl. Veterinaermed. A22: 346-350.

8. Hanawa, T. and Okita, N. 1989. J. Jpn. Vet. Med. Assoc. 42: $565-567$.

9. Hoogland, H. J. M. 1926. Arch. Tierheilkd. 54: 170-183.

10. Jasper, D. E. and Kanegis, L. A. 1946. Cornell Vet. 36: 262-267.

11. Kure, S., Shirai, W., and Yamada, F. 1973. J. Jpn. Vet. Med. Assoc. 26: 31-35.

12. Masegi, T., Kudo, T., and Yamaguchi, T. 1990. Jpn. J. Vet. Sci. 52: 635-637.

13. Mohanty, J., Ojha, S. C., Mitra, A. K., and Rao, A. T. 1971. Indian Vet. J. 48: 99-101.

14. Moulton, J. E. 1990. pp. 364-368. In: Tumors in Domestic Animals, 3rd ed. (Moulton, J. E. ed.), Univ. California Press, Berkeley, CA.

15. Nobel, T. A. and Neuman, F. 1962. Refuah Vet. 19: 220-221.

16. Pindborg, J. J. and Kramer, I. H. R. 1971. pp. 5-43. In: International Histological Classification of Tumors No. 5, Geneva, W H O.

17. Rao, A. T., Nayak, B. C., and Choudary, C. 1972. Indian J. Anim. Sci. 42: 353-354.

18. Poulet, F. M., Valentine, B. A., and Summers, B. A. 1992. Vet. Pathol. 29: 369-380.

19. Sastry, G. A., Venkatanarayana, J., Rao, P. R., and Christopher, J. 1967. Indian Vet. J. 44: 281-283.

20. Shortridg, E. E. and Cordes, D. O. 1971. N. Z. Vet. J. 19: 5-11.

21. Simu, G., Ivascu, I., and Simu, G. 1975. Zentralbl. Veterinaermed., A22: 791-796.

22. Slootweg, P. J. 1981. Oral Surg. 51: 266-276.

23. Van der Gaag, I. and Gruys, E. 1972. Tijdschr. Diergeneeskd. 97: 22-37.

24. Walsh, K. M., Denholm, L. J., and Cooper, B. J. 1987. J. Comp. Pathol. 79: 503-521. 